\title{
Formação Profissional para Surdos: Resgatando uma História ${ }^{1}$
}

\author{
Eliane Aparecida Pfeifer ${ }^{2}$ \\ EMEE Helen Kellr, São Paulo, Brasil.
}

\begin{abstract}
Resumo
Muitos são os desafios para que os surdos conquistem competência profissional. Relata-se aqui os resultados obtidos pelo programa de inclusão de surdos no trabalho conduzido na EMEE Helen Keller. Tal programa iniciou-se em 1970 e passou por um processo de amadurecimento com diversos enfoques. Abrange três fases distintas: fase I que trata da conscientização das questões do mundo do trabalho; fase II, qualificação profissional e fase III, colocação no mercado de trabalho. Os resultados obtidos neste estudo demonstram o papel das escolas e instituições e sua importância como contribuição na conquista da emancipação dos surdos em relação à vida profissional e à garantia do exercício de sua cidadania.
\end{abstract}

\section{Professional Formation for the Deaf: rescuing the history}

\section{Summary}

There are many challenges facing the deaf who wish to conquer professional competence. The results obtained in the program to include the deafin the work place done at EMEE Helen Keller are reported here. This program was started in 1970 and passed though a maturing process with diferent highlights. Three distinct phases are involved: phase I deals with the conciousness of questions about the work world; phase II, professional qualification and phase III, placement in the work market. The results obtained in this study shows the roles of schools and institutions and their importance in contributing to the conquest of deafs emancipation in relation to professionallife and the right to exercise full citizenship.

\section{Introdução}

Considerando a importância do trabalho na vida humana, pesquisadores e instituições passaram a enfocar e a trabalhar questões relativas ao tema.

Destacando os indivíduos portadores de deficiência, o processo de adquirir competência para exercer uma profissão e de alcançar maturidade social para conquistar um espaço no mundo do trabalho é um desafio que exige soluções diferenciadas e inovadoras, e o papel das escolas e instituições é fundamental para que possam conseguir enfrentar e obter êxitos num mercado de trabalho tão competitivo dos dias atuais.

Cabe portanto às escolas, sobretudo às escolas especiais levar os deficientes a um desenvolvimento pessoal e à socialização, oferecendo também um olhar amplo sobre as várias questões que envolvem o mundo do trabalho. É realmente importante, fundamental que as pessoas com deficiência conheçam suas aspirações, limitações e, a partir daí, construam o conhecimento necessário para integrá-lo na vida prática. Por esta razão, faz-se necessário oferecer programas que procurem sondar e analisar os interesses e aptidões e, a partir disto, orientar na escolha da profissão. Deve-se encaminhar os alunos para freqüentarem cursos profissionalizantes, treinamentos em

\footnotetext{
${ }^{1}$ Parte de dissertação de mestrado defendida na PUCCampinas. sob a orientação de G. P. Witter. enquanto bolsista da CAPES.

${ }^{2}$ Endereço: Rua Artur de Azevedo. 2013 apto. 51 CEP: 05404-015 - Pinheiros-SP Telefone: (011) 814-7614.
} 
empresas, ou mesmo, oferecer recursos de habilitação profissional na própria escola.

As Normas de Equiparação de Oportunidades para Pessoas com Deficiências (Nações Unidas 1996) em sua norma $n^{\circ} 6$ referente à educação estabelece que: as autoridades da educação comum são responsáveis pela educação de pessoas com deficiência em ambientes inclusivos. Elas devem garantir que a educação de pessoas com deficiência seja uma parte integrante do planejamento educacional nacional, do desenvolvimento de currículo e da organização escolar.

O art. $1^{\circ}$ do Decreto $n^{\circ} 2208$ que regulamenta os atligos 36 e de 39 a 42 da Lei 9.394, estabelece que o objetivo da educação profissional é: promover a transição entre a escola e o mundo do trabalho, capacitando jovens e adultos com conhecimentos e habilidades gerais $e$ especificas para o exercício de atividades produtivas.

E ainda em seu art. $2^{\circ}$ estabelece: a educação profissional será desenvolvida em articulação com o ensino regular ou em modalidades que contemplem estratégias de educação continuada, podendo ser realizada em escolas do ensino regular em instituições especializadas ou nos ambientes de trabalho.

O PNE - Plano Nacional de Educação proposto pela sociedade brasileira (1998) enfatiza que a educação profissional, formal e não formal. enquanto parte de um projeto educativo global e de uma política de desenvolvimento nacional e regional, deverá integrar-se ao sistema regular de ensino e articula-se na luta por uma educação pública, gratuita, laica e de qualidade para todos. Oferece como uma de suas diretrizes: reiterar, ainda em 1998, a educação profissional ao sistema regular de ensino, ampliando os recursos orçamentários especificamente destinados a esta modalidade.

Muitas discussões no nível nacional e internacional vêm enfocando o papel, tanto das escolas comuns, como das escolas especiais, no processo de inclusão dos deficientes no meio laboral e no meio social, como um elemento produtivo e ajustado.

Educar porém, alunos portadores de deficiência é um trabalho complexo. São necessários objetivos claros e o estabelecimento de planos concretos que atendam suas exigências e os levem a um comprometimento na construção da sociedade.

De acordo com Sassaki (1996) quando as escolas especializadas em atender o deficiente auditivo preparam um programa de formação profissional com vistas à inclusão desses deficientes no mercado formal de trabalho, devem levar em conta que o contato deles com o ambiente de trabalho deverá proporcionar a aquisição de conhecimentos que internalizados, lhes dão uma competência social. É participando de situações e práticas sociais que ocorre a aprendizagem que, por sua vez, desencadeia o processo de desenvolvimento.

Os portadores de deficiência auditiva são igualmente chamados a despertar e vencer os obstáculos internos e externos e alcançar uma efetiva competência profissional e social. Tanto os surdos como os profissionais dedicados ao tratamento da surdez sabem a importância que tem esta falta sensorial no comportamento do indivíduo.

Para Launay \& Maisonny (1996) pessoas com inabilidade nas áreas motora, intelectual e/ou sensorial, apresentam uma série de incapacidades que nem sempre viabilizam o desenvolvimento em nível desejado. E, no caso do portador de deficiência auditiva, essas limitações podem afetar, em maior ou menor grau, a sua personalidade e afetividade, criando dificuldades de comunicação mais ou menos notórias.

Sabe-se que a linguagem oral é social e funciona como um elo comum de interação entre as 
pessoas. A deficiência sensorial auditiva dificulta ou às vezes impede o indivíduo de adquirir linguagem oral comprometendo assim seu processo de socialização.

Referindo-se ao processo de emancipação do surdo, Franco (1999) enfatiza que educadores de surdos vivem um constante questionamento de como proporcionar condições concretas de aprendizagem para aqueles cujas história é marcada por uma trajetória de exclusão educacional e social. No caso brasileiro evidencia-se também, a falta de uma metodologia que atenda as especificidades da educação de surdos e que contemple currículo e material didático próprios. A Autora enfatiza a necessidade urgente em repensar a natureza da escola especial de surdos e de sua orientação curricular.

De fato, o processo de educação profissional e de empregabilidade pede hoje uma enorme mudança nas habilidades requeri das exigindo aprimoramento constante. Pode-se constatar isso nas publicações de Rawlings, Karchmer \& Allen (1999) onde estão registrados 149 programas desenvolvidos nos Estados Unidos que avaliam o interesse e a qualificação de estudantes surdos e nas pesquisas de Pfeifer (1998), Stahlman (1995) e Rodrigues 1990.

Skliar (1997) faz uma proposição nova indicando uma mudança de enfoque sobre as políticas sociais e educacionais sobre o portador de surdez que hoje é delimitada basicamente por modelos clínicos terapêuticos. Argumenta que se faz necessária a ampliação do horizonte curricular cultural e ideológico na educação dos surdos e denomina isso de "Estudos Surdos". Para este autor, deve-se abrir um campo de investigação e de proposições educacionais que através de um conjunto de concepções lingüísticas, multiculturais e antropológicas, se aproximem do mundo surdo, ou seja, de sua cultura, de sua identidade e reais necessidades.

Para Klein (1998) na elaboração de projetos educacionais para surdos se faz relevante considerar as ações reivindicatórias das associações de surdos que, juntamente com os movimentos de pessoas portadoras de deficiência, realizam campanhas no sentido de propagar os direitos dos cidadãos expressando suas reais necessidades.

Pode-se tomar por exemplo como referência importante no Brasil, o documento denominado "Que educação nós surdos queremos", elaborado pela comunidade surda da América Latina no PréCongresso que antecedeu o V Congresso Latino-Americano da Educação Bilingüe para Surdos em abril de 1999, ou nos estudos de Perlin (1999).

Em suma, o mundo está mudando constantemente e os órgãos responsáveis pela elaboração de políticas educacionais e de programas de atendimento, sobretudo referentes à formação profissional de portadores de deficiência têm, diante de si, por um lado, pessoas mais politizadas e conscientes de suas necessidades e dispostas a lutar por seus interesses e, de outro, o processo de globalização da economia que estabelece exigências de qualificação e competência para serem absorvidos pelo mercado de trabalho. Assim, há que se buscar sempre um aprimoramento e mudanças de paradigmas que atendam plenamente a todas essas exigências.

Pretende-se relatar neste trabalho de pesquisa, os resultados de um programa de formação profissional conduzido pela EMEDA HELEN KELLER nos últimos 29 anos, descrevendo os diferentes enfoques por que passou e os efeitos causados nos alunos deficientes auditivos. Os objetivos propostos por este estudo são: descrever o atendimento realizado aos alunos na $1^{\mathrm{a}}$ a fase do programa, ou seja, os grupos de sondagem vocacional e os grupos classe que receberam aulas da disciplina PIP- Programa de Informação Profissional (incorporada no currículo da escola desde 1995); descrever o número de alunos encaminhados ao ensino profissionalizante e em quais áreas 
fizeram a escolha da qualificação profissional; descrever o número de alunos que foram encaminhados ao mercado aberto de trabalho e em quais áreas fizeram suas opções profissionais e, fazer uma correlação entre os curso de habilitação profissional freqüentados com a área de inclusão no mercado de trabalho.

\section{Método}

Após a apresentação da instituição a que pertencem os sujeitos e breve histórico do programa de profissionalização nela mantido, é descrita a metodologia empregada para a coleta de dados de que se serviu o presente estudo.

Caracterização da Instituição e Histórico do Programa de Profissionalização

A Secretaria Municipal de Educação de São Paulo (SME), em seu Decreto ${ }^{\circ} 33.891$ de 16/12/93 instituiu a política de atendimento aos portadores de necessidades especiais. Tal política, se concretiza na especificidade de cada uma das seguintes modalidades: SAPNE - Sala de Atendimento aos Portadores de Necessidades Especiais; EMEDA - Escola Municipal de Educação Especial e, CEMAE - Centro Municipal de Atendimento Especial.

As EMEDA's são escolas especiais e destinam-se àqueles alunos que, pelo seu grau de dificuldade na comunicação, não conseguem acompanhar classes regulares por falta de um trabalho de estimulação da fala e da audição e de oportunidade de desenvolvimento de linguagem.

As cinco EMEDA's existentes na rede municipal de ensino de São Paulo são portanto, escolas especializadas cuja clientela é composta por alunos deficientes auditivos com perdas neurosensoriais moderadamente severas, severas e profundas que provém das diversas regiões de São Paulo e Grande São Paulo.

$\mathrm{O}$ atendimento às crianças deficientes auditivas na EMEDA Helen Keller surgiu de um movimento de pais que queriam ver seus filhos escolarizados e com um atendimento adequado às suas limitações. Na época (1951), a cidade de São Paulo não dispunha de recursos públicos que garantissem este atendimento. Foi então criado o $1^{\circ}$ Núcleo Educacional para Crianças Surdas e consagrou-se desta forma, o atendimento às crianças portadoras de deficiência auditiva e que não possuíam as mínimas condições de acompanhamento do ensino comum, na prefeitura de São Paulo.

Desde o ano de 1970, a EMEDA Helen Keller sentiu a necessidade de implantar um programa que viesse proporcionar condições de educação profissional e colocação no mercado de trabalho. Este programa surgiu sobretudo, para combater o estigma que acompanha as pessoas portadoras de deficiência auditiva que, em geral, são vistas pela sociedade como dependentes ou incapazes de produzir, de participar e também pouco conhece sobre suas limitações e potencial idades.

Assim, além dos componentes curriculares comuns, é desenvolvido um programa de formação profissional e colocação no mercado de trabalho dividido em três fases distintas:

- Fase 1 - Preparação para o mercado de trabalho;

- Fase 2 - Encaminhamento para o ensino profissionalizante para qualificação profissional e

- Fase 3 - Colocação e acompanhamento no mercado formal de trabalho. 
O projeto de formação profissional do deficiente auditivo e sua inserção no mercado formal de trabalho (SME 1996) tal como foi elaborado e executado pela Escola, compreende um processo de amadurecimento com diversas etapas. Durante todo o percurso, tem-se a preocupação de se romper os estigmas que estão ligados à figura do deficiente.

Este trabalho de formação profissional iniciou-se sistematicamente em 1970, através de um convênio entre a Prefeitura de São Paulo e o SENAI - e eram oferecidas vagas em alguns cursos para os quais eram encaminhados os alunos.

A partir de 1981, o trabalho começou a se estruturar de maneira mais abrangente, envolvendo maior número de alunos e melhor qualidade de atendimento, possibilitando assim condições de uma opção profissional mais adequada.

Em 1987, procurou-se implantar um trabalho em horários extracurriculares, formando vários grupos-classe de adolescentes com interesse na formação profissional e treinamento para o trabalho. Foram então montados na escola, cursos profissionalizantes nas áreas de datilografia, serviços gerais de escritório e computação.

No entanto, em 1989, este trabalho foi suspenso pela administração e a partir daí, procurouse, na medida do possível, dar continuidade ao programa, tentando minimizar a grande solicitação que era feita por parte dos alunos e pais em relação a cursos profissionalizantes e/ ou encaminhamento para o mercado formal de trabalho.

Com a implantação do curso supletivo em 1990, a demanda de alunos com necessidade de inserção no mercado de trabalho aumentou, exigindo um esforço maior de contato com as empresas para colocação profissional.

Em 1995, foi implantado oficialmente no currículo da EMEDA a disciplina PIP - Programa de Informação Profissional, no qual os alunos são instruídos semanalmente para que possam adquirir prontidão para atuar como profissional, ou seja, obter uma formação pessoal, como futuro trabalhador e estar conscientizado da necessidade e importância do trabalho. Também objetiva-se proporcionar uma visão crítica do mundo do trabalho, bem como das possibilidades que oferece.

Os aspectos principais da vida laboral eram trabalhados na disciplina, destacando-se: autoconhecimento; hábitos de responsabilidade e independência; perceber a importância de estar preparado para desenvolver uma atividade profissional e perceber-se como futuro trabalhador e elemento produtivo na sociedade.

O programa também objetiva formar uma consciência da imp011ância do trabalho para si mesmo (realização pessoal) e para a sociedade como um todo, e da imp011ância de desempenhar um papel de agente de modificação da sociedade.

Além da disciplina PIP, os alunos são trabalhados de forma coletiva durante eventos como: "Semana do Trabalhador" e "Semana da Conquista da Cidadania". Nestes eventos são destacados a imp011ância da luta de conquista de oportunidades de emprego e os caminhos para alcançar a evolução de carreira e sucesso profissional. Por fim, há empenho para que percebam que a luta pelas conquistas sociais é trabalho do grupo para os surdos. Deve ser empenho do cidadão bem como da união de seus pares.

Embora não haja no momento, dados sistematicamente analisados, os resultados obtidos com o desenvolvimento deste programa, sugerem a sua eficiência e a sua importância para que os alunos alcancem a integração no mercado competitivo de trabalho.

Atualmente, a disciplina PIP - Programa de Informação Profissional passou a denominar-se 
OT - Orientação para o Trabalho e está sendo oferecida somente para o ensino regular de 13 a 83 séries, sendo portanto, excluída do curso supletivo.

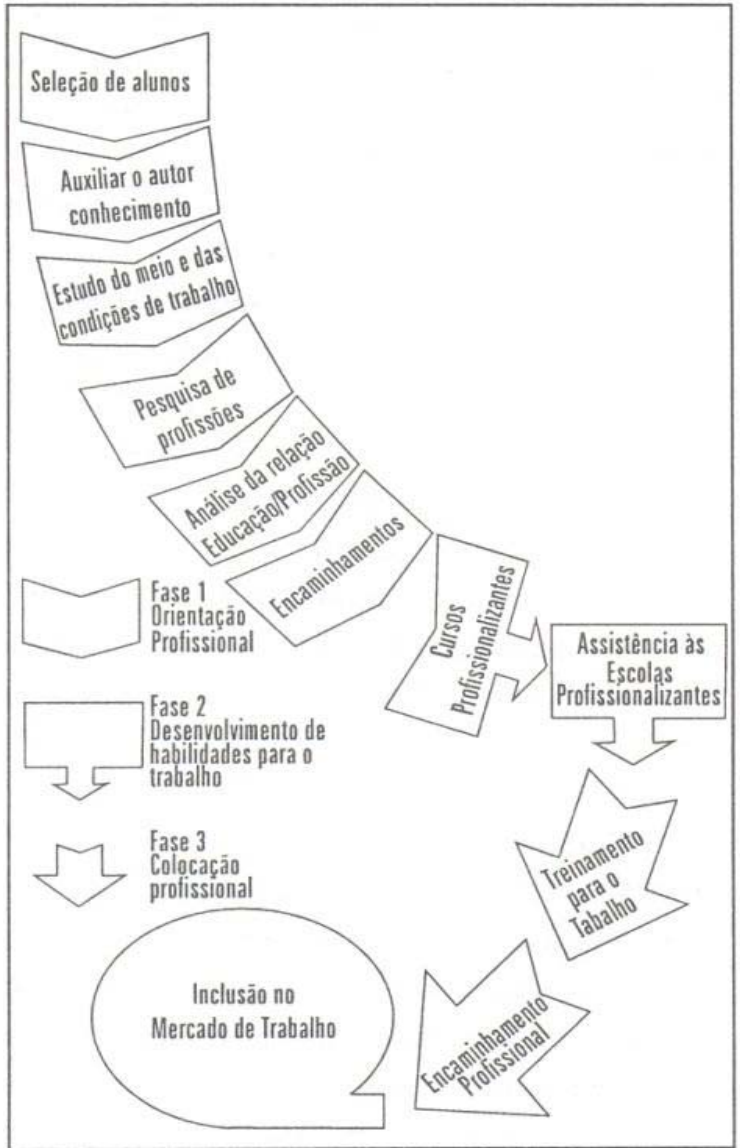

Figura 1. Passos do Programa de prontidão para o Trabalho

\section{Documentos Pesquisados}

A presente pesquisa baseou-se nos dados de registro do programa de preparação dos alunos da EMEDA Helen Keller com vistas à inclusão no mercado formal de trabalho, a saber:

- Relatório anual das atividades realizadas pelo programa de formação profissional;

- Gráficos e tabelas elaborados pela equipe de profissionalização da escola;

- Listas de encaminhamento dos alunos nas diversas fases do programa;

- Relatórios semestrais dos alunos atendidos na I a fase do projeto, ou seja, sondagem vocacional;

- Relatórios semestrais dos alunos atendidos na 23 fase, ou seja, encaminhamento ao ensino profissionalizante no SENAI, em escolas particulares e cursos desenvolvidos na própria escola;

- Registros elaborados pelo setor de serviço social da escola, referentes aos encaminhamentos ao mercado de trabalho. 


\section{Discussão e Análise dos Resultados}

A Tabela I ilustra bem os resultados dos diferentes momentos por que passou o Programa de Profissionalização da EMEDA Helen Keller. A cada administração municipal mudava-se a política de abordagem ao portador de surdez e isto afetava consideravelmente o atendimento oferecido aos alunos da escola.

Observa-se que nos anos de 1983 a 1988 houve o que se considera como um atendimento mais global no qual as três fases do programa funcionavam harmoniosamente para atender os educandos da escola.

No entanto, apesar da implantação da disciplina PIP em 1995, a qual abrange a $1^{\mathrm{a}}$ a fase do programa e que passou a atender um número considerável de alunos, houve uma diminuição no atendimento de continuidade, ou seja, diminuíram os encaminhamentos a cursos profissionalizantes (Fase II) e colocação no mercado de trabalho (Fase III).

\begin{tabular}{|c|c|c|c|c|c|c|c|c|}
\hline \multicolumn{9}{|c|}{ PROGRAMA DE EOUCACÃO PROFISSIONAL } \\
\hline ANO & \multicolumn{2}{|c|}{ FASEI } & \multicolumn{2}{|c|}{ FASE II } & \multicolumn{2}{|c|}{ FASE III } & \multicolumn{2}{|c|}{ TOTAL } \\
\hline & Freq. & 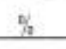 & Freq. & $\%$ & Freq. & $\mathrm{s}$ & Freq. & if \\
\hline 1970 & & & 2 & 0.4 & 0 & 0.8 & 2 & 0,1 \\
\hline 1971 & & & 0 & 0,0 & 0 & 0,0 & 1 & 0.0 \\
\hline 1972 & & & 6 & 1.2 & 6 & 1.7 & 12 & 0.5 \\
\hline 1973 & & & 38 & 7.8 & 17 & 4.7 & 55 & 25 \\
\hline 1974 & & & 4 & 0,8 & 2 & 0.6 & 6 & 0.3 \\
\hline 1975 & & & 12 & 24 & 2 & 0.6 & 14 & 0,6 \\
\hline 1976 & & & 4 & 0,8 & 3 & 0.8 & 7 & 0,3 \\
\hline 1977 & & & 1 & 0.2 & 1 & 0,3 & 2 & 0,1 \\
\hline 1978 & & & 2 & 0.4 & 0 & 0,0 & 2 & 0.1 \\
\hline 1979 & & & 0 & 0.0 & 0 & 0.0 & 0 & 0.0 \\
\hline 1980 & & & 34 & 6.9 & 4 & 1,1 & 38 & 1.7 \\
\hline 1981 & & & 27 & 5,5 & 2 & 0.6 & 29 & 1,3 \\
\hline 1982 & & & 24 & 4,9 & 10 & 28 & 34 & 1,5 \\
\hline Subtotal & & & 154 & 31,5 & 47 & 13.1 & 201 & 9,0 \\
\hline 1983 & 51 & 3.7 & 17 & 3.5 & 0 & 9.0 & 68 & 3,1 \\
\hline 1984 & 47 & 3.4 & 21 & 4,3 & 3 & 0.8 & 71 & 3.2 \\
\hline 1985 & 40 & 2.9 & 41 & 8.4 & 4 & 1,1 & 85 & 3.8 \\
\hline 1986 & 83 & 6,0 & 3 & 0,6 & 6 & 1,7 & 92 & 4,1 \\
\hline 1987 & 38 & 28 & 56 & 11,4 & 11 & 3.1 & 105 & 4.7 \\
\hline 1988 & 92 & 6.7 & 96 & 19,6 & 12 & 3,3 & 200 & 9.0 \\
\hline Suhtotal & 351 & 25.5 & 234 & 47,8 & 36 & 10,0 & 621 & 27.9 \\
\hline 1999 & & & 13 & 2.7 & 10 & 28 & 23 & 1.0 \\
\hline 1990 & & & 13 & 2.7 & 5 & 1.4 & 18 & 0.8 \\
\hline 1991 & & & 12 & 24 & 48 & 13,3 & 60 & 2.7 \\
\hline 1992 & & & 26 & 5,3 & 27 & 7.5 & 53 & 2,4 \\
\hline 1993 & & & 10 & 2.0 & 26 & 7,2 & 36 & 1.6 \\
\hline 1994 & & & 5 & 1.0 & 39 & 10.8 & 44 & 20 \\
\hline Subtotal & & & 79 & 15,1 & 155 & 43.1 & 234 & 10,5 \\
\hline 1995 & 337 & 24,4 & 1 & 0.2 & 10 & 2,8 & 348 & 15.6 \\
\hline 1996 & 291 & 21.1 & 1 & 0.0 & 3 & 0.8 & 294 & 13,2 \\
\hline 1997 & 206 & 14,9 & $B$ & 1,6 & 18 & 5.0 & 232 & 10,4 \\
\hline 1998 & 191 & 13.9 & 14 & 2.9 & 91 & 25,3 & 296 & 13,3 \\
\hline Suthatal & 1025 & 74,6 & 23 & 4,7 & 122 & 33,9 & 1170 & 52,6 \\
\hline Total & 1376 & 99,8 & 490 & 100 & 360 & 100 & 2226 & 100 \\
\hline
\end{tabular}

Tabela 1 - Histórico do Programa de Formação Profissional 
Em 1998, houve um aumento de atendimento na fase 3 (colocação no mercado de trabalho), porém este aumento ocorreu porque duas das empresas que contratam os portadores de surdez fizeram uma proposta de estágio remunerado sem perspectiva de contratação efetiva, porém, que possibilitava o atendimento de um número maior de alunos.

Em relação aos educandos que foram encaminhados aos cursos profissionalizantes, verificouse que houve uma grande variação de opções profissionais o que levou a aglutinar as respostas em três tipos de categorias: Comércio, Indústria e Serviços. A categoria Comércio englobou as profissões na área de Informática (6,33\%), Datilografia (17,55\%), Desenho Comercial (0,2\%), Letrista $(0,2)$, Serviços Gerais de Escritório (3,27\%) e Padeiro (0,41\%). A categoria Indústria aglutinou os cursos de Ajustador Mecânico (2,04\%), Cerâmica (1,02\%), Compositor Gráfico $(7,76)$, Confecção de Calçados (18,16\%), Costura Industrial (14,08\%), Desenho Gráfico e Publicidade (0,41\%), Desenho Mecânico (0,41\%), Encadernação (6,63\%), Modelagem (0,82\%), Montagem Gráfica $(0,82 \%)$, Retoque de Fotolito $(3,27 \%)$ e Torneiro Mecânico $(9,59 \%)$. Já a categoria Serviços, reuniu os cursos de: Confeiteiro (0,2\%), Eletricista de Manutenção $(0,41 \%)$, Eletrônica de Âutos $(0,2 \%)$, Lustrador de Móveis $(0,2 \%)$, Marceneiro (0,41 \%), Mecânica de Auto Diesel $(1,43 \%)$, Pintor/Pedreiro $(0,2 \%)$, Serigrafia $(1,84 \%)$, Reparador de Eletrodomésticos $(0,61 \%)$, Mecânica de Auto (0,2\%), Tapeceiro Estofador (0,2\%) e Desenho Artístico (1,22\%).

Estes dados demonstram as diferentes áreas escolhidas pelos alunos referentes à qualificação profissional. Somando-se os cursos profissionalizantes referentes, por exemplo, à Artes Gráficas (Compositor Gráfico, Desenho Gráfico e Publicidade, Encadernação, Montagem Gráfica e Retoque de Fotolito) obtêm-se uma porcentagem de 18,79 e, no entanto, somente 5\% desses alunos foram absorvidos pelo mercado formal de trabalho.

A tabela 2 ilustra a somatória dos alunos que fizeram a qualificação profissional e foram inseridos no mercado de trabalho.

\begin{tabular}{|c|cc|cc|c|}
\hline \multirow{2}{*}{ Categorias } & \multicolumn{2}{|c|}{$\begin{array}{l}\text { Qualificação } \\
\text { Profissional }\end{array}$} & \multicolumn{2}{|c|}{$\begin{array}{c}\text { Mercado de } \\
\text { Trabalho }\end{array}$} & Total \\
\cline { 2 - 6 } & Fref. & $\%$ & Fref. & $\%$ & \\
\hline Comércio & 137 & 28 & 56 & 16 & 33,98 \\
\hline Indústria & 318 & 6 & 206 & 57 & 23,92 \\
\hline Serviços & 35 & 65 & 98 & 27 & 29,84 \\
\hline Total & 490 & 100 & 369 & 100 & \\
\hline
\end{tabular}

Tabela 2 - Alunos com qualificação profissional e alunos inseridos ou não no mercado de trabalho (por categorias)

Realizado o teste de homogeneidade estatística para $\mathrm{H}_{\mathrm{o}}$ : não há preferência por categoria de curso e $\mathrm{H}_{\mathrm{a}}$ : há diferença de preferência por categoria de curso, sendo n. sigo $=0,05$ e $\mathrm{X}_{\mathrm{c}}^{2}=5,99$. Foi obtido $\mathrm{H}_{0}: \mathrm{X}_{\mathrm{o}}{ }_{\mathrm{o}}=252,05$, portanto, significantemente estão concentrados na categoria Indústria. Também é significante o fato de não haver praticamente busca de preparo na categoria Serviços.

Quanto aos alunos que foram encaminhados ao mercado formal de trabalho, houve o mesmo procedimento, ou seja, foram divididos nas mesmas três categorias sendo que o Comércio aglutinou as profissões de Agente Administrativo (1,67\%), Auxiliar Bancário (0,83\%), Aux. Estoquista (2,78\%), Aux. de Tesouraria (4,44\%), Aux. de Padeiro (1,11\%), Desenho Comercial $(0,56 \%)$, Digitador $(3,89 \%)$ e Mensageiro (0,28\%). Na categoria Indústria, as profissões foram reunidas em: Ajudante Geral (8,61\%), Ajudante de Produção (11,39\%), Atendente Júnior (0,83\%), Aux. de 
Acabamento Gráfico (1,11\%), Aux. de Confecção de Calçados (1,94\%), Aux. de Confecção de Óculos $(0,56 \%)$, Aux. de Ourives $(1,11 \%)$, Aux. de Produção de Autopeças $(5,56 \%)$, Ceramista $(2,22 \%)$, Compositor Gráfico $(0,83 \%)$, Costureira (13,61\%), Embalador $(5,28 \%)$, Encadernador $(1,67 \%)$, Retocador de Fotolito $(1,39 \%)$ e Overloquista $(1,11 \%)$. Com relação à categoria Serviços, foram englobadas as seguintes profissões: Ajudante Publicitário (0,56\%), Aux. de Artesão (2,5\%), Aux. Mecânica de Auto (2,5\%), Aux. de Pintura (0,83\%), Desenhista (0,56\%), Marceneiro (0,56\%), Serigrafia (0,56\%), Tapeceiro Estofador (0,56\%) e Aux. de Postagem (17,78\%).

Foi realizado um teste estatístico $\mathrm{X}^{2}$ para a análise das respostas dos alunos que foram colocados no mercado de trabalho. Realizado o teste de homogeneidade estatística para $\mathrm{H}_{0}$ : não há diferença quanto a ocorrência de áreas em que estão empregados e $\mathrm{H}_{\mathrm{a}}$ : existe diferença quanto a ocorrência de áreas em que estão empregados, sendo n. sig. $=0,05$ e $\mathrm{X}_{\mathrm{c}}{ }_{\mathrm{c}}=5,99$. Foi obtido $\mathrm{H}_{\mathrm{o}}: \mathrm{X}^{2}{ }_{\mathrm{o}}$ $=127,32$, portanto, significantemente os alunos estão pouco empregados na área de comércio (apesar do investimento no preparo). Significantemente, a área que mais vem empregando é a industrial.

O mesmo teste foi realizado com cada uma das diferentes categorias, ou seja, Comércio, Indústria e Serviços, para verificar a relação entre os que foram habilitados profissionalmente e os que foram empregados.

Realizado o teste de homogeneidade estatística para $\mathrm{H}_{0}$ : não há diferença entre a freqüência de pessoas preparadas e de pessoas empregadas e $\mathrm{H}_{0}$ : existe diferença entre a freqüência de pessoas preparadas e de pessoas empregadas, sendo n. sig. $=0,05$ e $\mathrm{X}_{\mathrm{c}}=3,84$.

Foi obtido para a categoria Comércio $\mathrm{H}_{\mathrm{o}}: \mathrm{X} 2 \mathrm{o}=33,98$, portanto, significantemente há mais pessoas preparadas do que vagas preenchidas no mercado no setor do Comércio.

Foi obtido para a área da Indústria $\mathrm{H}_{\mathrm{o}}: \mathrm{X}^{2} 0=23,92$, portanto, significantemente pode-se concluir que também no setor industrial se está preparando mais pessoas do que há demanda.

Foi obtido para a área dos Serviços $\mathrm{H}_{\mathrm{o}}: \mathrm{X}_{\mathrm{o}}=29,84$, portanto, no caso de Serviços ocorreu o inverso, sendo significantemente maior a demanda por empregados do que o número dos que tiveram preparo.

\section{Conclusões}

A análise deste Programa de Formação Profissional para deficientes auditivos permite concluir que:

- a maioria dos alunos que passaram pela qualificação profissional foi colocada no mercado formal de trabalho;

- dificuldade de trabalho nas áreas em que fez curso profissionalizante, exceto em relação à Costura Industrial ( $71 \%$ dos alunos treinados conseguiram colocação no mercado de trabalho);

- tendência dos alunos em fazer cursos de qualificação profissional na categoria Comércio e conseqüente dificuldade de, posteriormente, serem absorvidos pelo mercado de trabalho e,

- grande porcentagem de alunos colocados em serviços gerais, que na realidade apresentam pouca exigência em relação à habilitação profissional. 


\section{Referências}

Launay, C. e Maisonny S. B. (1986). Distúrbios da linguagem da fala e da voz na infância. São Paulo: Roca. Klein, M. (1998). Os discursos sobre surdez, trabalho e educação e a formação do surdo trabalhador. In: Carlos Skliar (org.) A surdez: Um olhar sobre as diferenças.(75-94). Porto Alegre: Mediação.

Nações Unidas (1996). Normas sobre a equiparação de oportunidades para pessoas com deficiência. Tradução de Marisa do Nascimento Paro. São Paulo: CVI-NA/APADE. Tradução de The Stanrd rules on the equalization of oportunities for persons with disabilities.

Perlin G.T.T. (1999). Identidades Surdas. Tese de Mestrado em Educação da Universidade Federal do Rio Grande do Sul - URFGS.

Pfeifer, E. A. (1998). Deficiente auditivo: competência social e inclusão no mercado de trabalho. Tese de Mestrado. PUC-Campinas. Campinas.

Rodrigues, N.A. (1990). Escolarização e profissionalização do aluno portador de deficiência auditiva maior de 14 anos na Rede Estadual de Ensino de $1^{\circ}$ Grau. São Paulo: Tese de Mestrado em Distúrbios da Comunicação da PUCSP.

Sassaki, R.K. (1996). O Processo de transição escola/ trabalho. Curso de Capacitação de Professores e Profissionais de Educação Especial. São Paulo. S.M.E. (Mimeo).

Secretaria Municipal de Educação (SME). (1996). Currículos e programas de Educação Especial. São Paulo, SME.

Skliar C. (1997). A reestruturação curricular e as políticas educacionais para as diferenças: O caso dos surdos (244-280). In: Luis H. da Silva; José C. de Azevedo e Edmilson S. dos Santos Identidade Social e a construção do conhecimento. Porto Alegre: Ed. Secretaria Municipal de Educação de Porto Alegre Prefeitura Municipal de Porto Alegre.

Stahlman, B.L. (1995). Social interation: assessment and intervention with regard to student who are deaf. American Annals of the Deaf 140 (3),293303. 